\title{
GERMINAÇÃO E VIGOR DE SEMENTES DE ARROZ ARMAZENADAS EM DIFERENTES TIPOS DE EMBALAGEM EM TRÊS MICRORREGIÕES DO ESTADO DA PARAÍBA
}

\author{
Rossana Maria Feitosa de Figueirêdo ${ }^{1}$, Mario Eduardo R.M. Cavalcanti Mata ${ }^{2}$ \\ e Vicente de Paula Queiroga ${ }^{3}$
}

\begin{abstract}
RESUMO
Esta pesquisa teve como objetivo avaliar a influência de diferentes locais de armazenamento no Estado da Paraíba, representativo das microrregiões homogêneas do Litoral Paraibano (João Pessoa), Agreste da Borborema (Campina Grande) e Depressão do Alto Piranhas (Patos) em condições de armazém aberto, sobre a germinação das sementes de arroz (Oryza sativa $L$.) em função dos diferentes tipos de embalagem (recipientes metálicos e sacos de aniagem) durante o período de seis meses. $O$ experimento foi montado segundo um esquema fatorial $3 \times 2 \times 7$, utilizando-se o delineamento inteiramente casualizado, com quatro repetições. As avaliações foram feitas mensalmente, seguindo-se a orientaçăo prescrita pelas "Regras de Análise de Sementes", exceto para o número de sementes, que foi de 200, em 4 repetições de 50 sementes. Diante dos resultados obtidos, concluiu-se que as sementes de arroz armazenadas nos diferentes tipos de embalagem e nas condições ambientais das três localidades, apresentaram as menores perdas de germinação (4\%) e vigor $(6,5 \%)$ no final do período, em Campina Grande; na localidade de João Pessoa, a menor perda foi verificada na embalagem metálica, germinação $(28,1 \%)$ e vigor $(31,5 \%)$ e, em Patos, a menor perda da viabilidade das sementes ocorreu na embalagem saco de aniagem, com $12,6 \%$ para germinação e $26,3 \%$ para vigor.
\end{abstract}

Palavras-chave: armazenagem, embalagem, germinação, arroz

\section{GERMINATION AND VIGOR OF RICE SEEDS SUBJECT TO DIFFERENT TYPES OF PACKAGING IN THREE MICRO-REGIONS IN THE STATE OF PARAÍBA}

\begin{abstract}
The purpose of this study was to evaluate the influence of different storing locations in the State of Paraíba, which is representative of the homogeneous micro-regions of the coastal area of Paraíba (João Pessoa), Borborema Rural Area (Campina Grande), and Alto Piranhas Depression (Patos), under open storage conditions, on the germination of rice seeds (Oryza sativa $\mathrm{L}$.) relating to different types of packaging (metalic containers and burlap sacks) during a six months period. The experiment was set according to a factorial scheme $3 \times 2 \times 7$, using the completely randomized design, with four replications. Evaluations were made monthly, following the guidelines prescribed by the "Seeds Analyses
\end{abstract}

\footnotetext{
${ }^{1}$ Professora Assistente - UFPB/DEAg/NTA Av. Aprígio Veloso, 882 - CP 10.087 CEP 58109-970 - Campina Grande, PB

2 Professor Adjunto do DEAg/NTA/UFPB. e-mail: mmata (a) deag.ufpb.br

${ }^{3}$ Pesquisador EMBRAPA/CNPA/PB
} 
Rules", except for the number of seeds (200) in four replications of 50 seeds. Considering the results obtained, it was concluded that the rice seeds stored in the different types of packing and in the environmental conditions of the three locations presented the lowest losses in germination (4\%) and vigor $(6,5 \%)$ at the end of the period in Campina Grande. In João Pessoa, these losses were lowest in the metallic package $(28,1 \%$ in germination and $31,5 \%$ in vigor), and in Patos in the burlap sacks, with $12,6 \%$ germination and $23,3 \%$ vigor losses.

Key words: storage, packaging, germination, rice

\section{INTRODUÇÃO}

O arroz é, dentre os diversos cereais cultivados no mundo, um dos mais importantes, por se tratar de um alimento básico da maioria da população mundial e uma das culturas mais antigas.

De acordo com os dados da Fundação Instituto Brasileiro de Geografia e Estatística (Fundação IBGE, 1991) o arroz é cultivado em vários Estados brasileiros e se destacam como grandes produtores, Rio Grande do Sul, Maranhão, Mato Grosso e Minas Gerais.

A produção de arroz na Paraíba está muito aquém da demanda pelo produto e, apesar do Estado possuir elevado potencial, em termos de várzea, topografia e mananciais de água para exploração rizícola, produz apenas $20 \%$ da sua demanda, tendo que importar $80 \%$ de outros Estados brasileiros (Barreto, 1986). As duas microrregiões de destaque onde o arroz é produzido na Paraíba, são: Depressão do Alto Piranhas e Sertão de Cajazeiras, as quais representam 43 e $33,9 \%$ da produção, respectivamente (Santos \& Bosco, 1984).

A escassez de pesquisas sobre lécnicas de armazenamento de sementes de arroz no Estado, torna praticamente impossível recomendar procedimentos corretos para sua conservação. A maioria das pesquisas sobre a conservação de sementes de arroz no Brasil foi eletuada pricipalmente nas regiões Centro-Oeste e Sul, e os resultados não podem ser extrapolados para a região Nordeste, mais especificamente para a Paraíba, em virtude da grande diferença climática.

Esta pesquisa teve como objetivo avaliar a influência de diferentes locais de armazenamento no Estado da Paraíba, representativos das microrregiões homogêneas do Litoral Paraibano (João Pessoa), Agreste da Borborema (Campina Grande) e Depressão do Alto Piranhas (Patos) em condições de armazenagem aberta, sobre a germinação e vigor das sementes de arroz acondicionadas em diferentes tipos de embalagem (recipientes metálicos e sacos de aniagem) durante o período de seis meses.

\section{MATERIAL E MÉTODOS}

Este trabalho foi desenvolvido no Núcleo de Tecnologia em Armazenagem (NTA) nas dependências do Laboratório de Processamento e Armazenamento de Produtos Agrícolas do Departamento de Engenharia Agrícola (DEAg) na Universidade Federal da Paraíba -UFPB.

As sementes de arroz (Oryza sativa $L$.), cultivar BR- IRGA409, ulilizadas neste experimento, foram adquiridas no perímetro iriggado de São Gonçalo, município de Souza, Estado da Paraíba, no ano de 1993.

Na colheita, as sementes possuíam teor de umidade de $21 \%$ b.u., tendo sido beneficiadas e postas para secar ao sol; depois foram acondicionadas em dois tipos de embalagem: recipientes metálicos $\left(E_{1}\right)$ com capacidade para $5 \mathrm{~kg}$ e em sacos de aniagem $\left(\mathrm{E}_{2}\right)$ com $10 \mathrm{~kg}$. Durante o acondicionamento tomou-se uma amostra representativa do lote para avaliação da qualidade fisiológica, obtendo-se uma germinação de $98 \%$ e teor de umidade de $12,3 \%$ b.u.

As sementes embaladas foram levadas para os municípios de João Pessoa $\left(L_{1}\right)$, Campina Grande $\left(L_{2}\right)$ e Patos $\left(L_{3}\right)$, representativos das microrregiốes homogêneas: Litoral Paraibano, Agreste da Borborema e Depressão do Alto Piranhas, respectivamente, e colocadas em armazéns abertos sob condições ambientais durante o período de janeiro a junho de 1993, sem controle de temperatura e de umidade relativa do ar.

As sementes foram armazenadas durante seis meses, sendo retiradas amostragens mensais para os testes de germinação e vigor.

\section{Teste de germinação e vigor}

O teste de germinação foi efeluado seguindo-se a orientação prescrita pelas "Regras para Análise de Sementes" (Brasil, 1992) com 200 sementes em quatro repetições de 50 sementes, usandose como substrato o papel Germitest, em rolo, com duas folhas na base e uma na cobertura, previamente umedecidas com água destilada; em seguida, os rolos foram colocados em recipientes de plástico com inclinação de $45^{\circ}$ dentro de um germinador mantido a temperatura de $30^{\circ} \mathrm{C} \pm 0,5^{\circ} \mathrm{C}$, enquanto a contagem foi realizada nos quinto e décimo quarto dias depois da semeadura. Para o teste de vigor foi utilizado o teste indireto da primeira contagem da germinação.

\section{Teor de umidade}

$\mathrm{O}$ teor de umidade das sementes de arroz foi determinado pelo método da estufa, a $105^{\circ} \mathrm{C} \pm 3^{\circ} \mathrm{C}$ durante 24 horas, de acordo com as Regras para Análise de Sementes (Brasil, 1992).

\section{Análise estatística}

A análise estatística dos dados de germinação e vigor foi realizada utilizando-se o delineamento inteiramente casualizado, no esquema fatorial $3 \times 2 \times 7$ (3 locais de armazenamento, 2 tipos de embalagem e 7 períodos de armazenamento) com quatro repetições para os parâmetros em estudo. As amostragens foram realizadas mensalmente, durante seis meses de armazenamento, e as análises de variância foram feitas utilizando-se o programa computacional denominado SOC (Paniago el al., 1987). A comparação entre médias foi feita através do teste de Tukey, a nível de $5 \%$ de probabilidade (Gomes, 1982). Os resultados de germinação e vigor foram transformados em $\mathrm{X}=\operatorname{arc}$ sen $(\mathrm{P} /$ $100)^{0,5}$, em que $\mathrm{P}$ é a percentagem (Snedecor, 1966) para efetivação da análise de variância. 


\section{RESULTADOS E DISCUSSÃO}

Os dados médios mensais de temperatura e umidade relativa das três localidades onde a armazenagem das sementes de arroz foi realizada, são mostrados na Figura 1 e os teores de umidade das sementes estão na Figura 2.

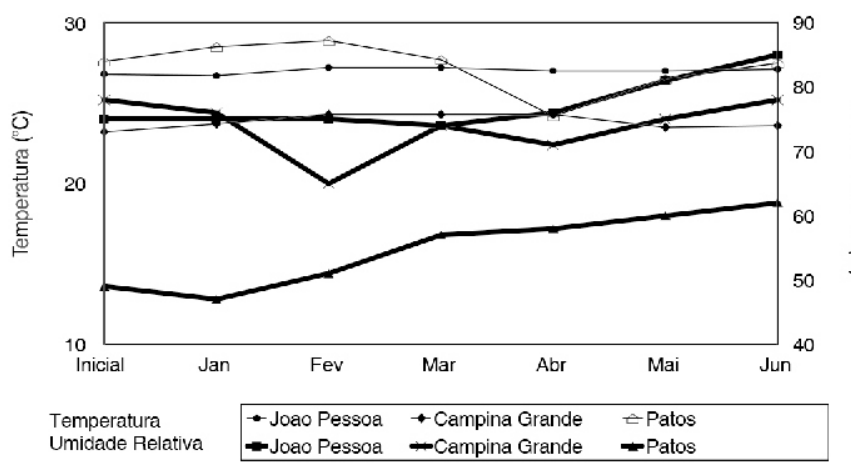

Figura 1. Médias mensais de temperatura e umidade relativa nas localidades de João Pessoa, Campina Grande e Patos, durante o período de armazenamento das sementes de arroz

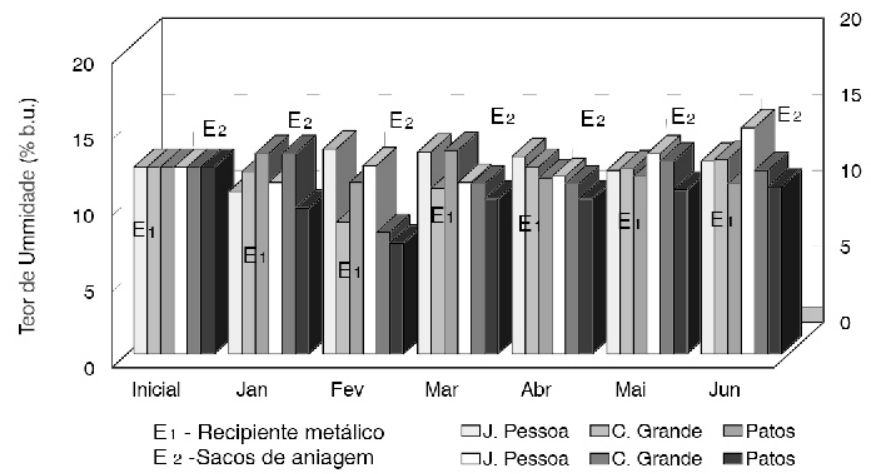

Figura 2. Médias mensais de teores de umidade das sementes de arroz durante o período de armazenamento nas localidades de João Pessoa, Campina Grande e Patos

\section{Germinação e Vigor}

Os resultados das análises estalísticas referentes à germinação e vigor das sementes de arroz, em função dos tipos de embalagem, locais de conservação e períodos de armazenamento, encontram-se nas Tabelas de 2 a 6 e na Tabela 1 acham-se os valores médios da germinação e vigor das sementes de arroz para as diversas localidades, tipos de embalagem e períodos de armazenamento. Observa-se, nesta Tabela, que tanto a germinação quanto o vigor das sementes de arroz diminuíram ao longo de seis meses de armazenamento, embora se observe que esla diminuição é menor no município de Campina Grande, independentemente da embalagem usada.

Na Tabela 2 é apresentada a análise de variância da germinação e do vigor das sementes de arroz, com os dados transformados em arc sen $(\mathrm{P} / 100)^{0,5}$ de acordo com Snedecor (1966). Verifica-se que para todos os fatores estudados e suas interações, houve efeitos significativos a nível de $1 \%$ de probabilidade pelo teste de $\mathrm{F}$.

Os valores médios da germinação das sementes de arroz para os fatores localidades, tipos de embalagem e períodos de armazenamento, encontram-se na Tabela 3 , na qual se constata que, dentre as três localidades onde as sementes foram
Tabela 1. Valores médios da germinação e vigor das sementes de arroz para as diferentes embalagens e localidades durante o período de armazenamento

\begin{tabular}{|c|c|c|c|c|c|c|}
\hline \multirow{3}{*}{ Mês } & \multicolumn{6}{|c|}{ Localidades } \\
\hline & \multicolumn{2}{|c|}{ João Pessoa } & \multicolumn{2}{|c|}{ Campina Grande } & \multicolumn{2}{|c|}{ Patos } \\
\hline & Germinação & Vigor & Germinação & Vigor & Germinação & Vigor \\
\hline & \multicolumn{6}{|c|}{ Recipientes metálicos $\left(\mathrm{E}_{1}\right)$} \\
\hline 0 & 98,0 & 96,0 & 98,0 & 96,0 & 98,0 & 96,0 \\
\hline 1 & 94,0 & 82,0 & 93,0 & 93,0 & 86,0 & 76,0 \\
\hline 2 & 91,0 & 80,5 & 91,5 & 85,0 & 81,0 & 69,0 \\
\hline 3 & 89,5 & 80,0 & 93,5 & 89,5 & 84,0 & 75,0 \\
\hline 4 & 92,0 & 88,0 & 88,0 & 76,5 & 87,5 & 79,0 \\
\hline 5 & 90,5 & 84,5 & 92,0 & 90,5 & 83,0 & 78,0 \\
\hline \multirow[t]{2}{*}{6} & 76,5 & 73,0 & 92,0 & 87,0 & 80,0 & 74,0 \\
\hline & \multicolumn{6}{|c|}{ Sacos de aniagem $\left(\mathrm{E}_{2}\right)$} \\
\hline 0 & 98,0 & 96,0 & 98,0 & 96,0 & 98,0 & 96,0 \\
\hline 1 & 92,0 & 82,3 & 96,0 & 96,0 & 90,0 & 75,0 \\
\hline 2 & 86,5 & 83,0 & 90,0 & 75,0 & 95,0 & 90,0 \\
\hline 3 & 43,0 & 48,5 & 92,0 & 87,0 & 82,0 & 66,5 \\
\hline 4 & 46,5 & 38,5 & 93,0 & 89,5 & 89,0 & 76,5 \\
\hline 5 & 43,5 & 37,5 & 90,0 & 86,0 & 89,5 & 77,5 \\
\hline 6 & 40,5 & 36,5 & 94,0 & 87,0 & 87,0 & 76,0 \\
\hline
\end{tabular}

Tabela 2. Análise de variância da germinação e vigor das sementes de arroz para diferentes embalagens, localidades de conservação e períodos de armazenamento

\begin{tabular}{lrrr}
\hline \multicolumn{1}{c}{ Fonte de Variação } & GL & \multicolumn{2}{c}{ Quadrado Médio } \\
& & Germinação & \multicolumn{1}{c}{ Vigor } \\
\hline Localidade & 2 & $1.694,08 * *$ & $1.779,80 * *$ \\
Embalagem & 1 & $705,48 * *$ & $772,83 * *$ \\
Período & 6 & $988,15 * *$ & $1.108,93 * *$ \\
Local x embalagem & 2 & $1.806,91 * *$ & $1.034,28 * *$ \\
Local x período & 12 & $223,79 * *$ & $221,57 * *$ \\
Embalagem x período & 6 & $185,70 * *$ & $192,91 * *$ \\
Local x embalagem x período & 12 & $145,45 * *$ & $189,91 * *$ \\
Resíduo & 126 & 5,28 & 3,79 \\
Total & 167 & - & \\
CV & \multicolumn{4}{c}{$3,29 \%$} & $3,02 \%$ \\
\hline ("Sigmificativo a nível de 1\% de probabilidade
\end{tabular}

"Significativo a mível de $1 \%$ de probabilidade

armazenadas, a que melhor preservou o poder germinativo e o vigor das sementes de arroz foi Campina Grande, tendo em vista as condições climáticas nesta localidade serem as mais favoráveis, concordando com Bacchi (1958) e Miranda (1967) quando afirmam que as condições climáticas influenciam decisivamente na viabilidade das sementes durante o armazenamento.

Para o fator embalagem, o poder germinativo e o vigor das sementes de arroz mostram que os recipientes metálicos (lata) apresentaram, de modo geral, melhor comportamento, fato este também comprovado por Paiva et al. (1972) e Pimentel et al. (1978) quando realizaram experimentos no Nordeste e verificaram que em ambientes naturais os silos metálicos foram as embalagens que proporcionaram a melhor conservação da qualidade fisiológica das sementes.

Quanto ao fator período de armazenamento, a Tabela 3 revela que tanto o valor médio da germinação quanto o do vigor das sementes de arroz, tendem a decrescer significativamente ao 
Tabela 3. Valores médios da germinação e vigor das sementes de arroz para os fatores localidades, embalagens e períodos de armazenamento

\begin{tabular}{|c|c|c|c|c|}
\hline \multirow[t]{2}{*}{ l'alores } & \multicolumn{2}{|c|}{ Transformados ${ }^{1}$} & \multicolumn{2}{|c|}{ Originais (\%) } \\
\hline & Gicrminaçâa & Vigor & Gicrminaçào & Vigor \\
\hline \multicolumn{5}{|l|}{ 1. Localidade } \\
\hline * Jodo Pessoa $\left(\mathrm{L}_{1}\right)$ & $64,12 \mathrm{c}$ & $59,49 \mathrm{c}$ & 81 & 74 \\
\hline * Campina Grande $\left(\mathrm{L}_{2}\right)$ & 75,08 a & $70,61 \mathrm{a}$ & 93 & 89 \\
\hline$*$ Patos $\left(L_{2}\right)$ & $70,46 \mathrm{~b}$ & $63,43 \mathrm{~b}$ & 89 & 80 \\
\hline \multicolumn{5}{|l|}{ 2. Гimbalagem } \\
\hline * Recipiente Metálico $\left(L_{1}\right)$ & $71,94 \mathrm{a}$ & $66,65 \mathrm{a}$ & 90 & 84 \\
\hline Saco de Aniagem $\left(\mathrm{L}_{2}\right)$ & $67,84 b$ & $62,36 \mathrm{~b}$ & 86 & 78 \\
\hline \multicolumn{5}{|l|}{ 3. Periodo de Armazenamento } \\
\hline *7cro mês $\quad\left(\mathrm{P}_{0}\right)$ & $82,01 \mathrm{a}$ & $78,55 \mathrm{a}$ & 98 & 96 \\
\hline * Primciro mês $\left(\mathrm{P}_{1}\right)$ & $73,93 \mathrm{~b}$ & $67,40 \mathrm{~b}$ & 92 & 85 \\
\hline * Scgundo mês $\left(\mathrm{P}_{2}\right)$ & $71,25 \mathrm{c}$ & $64,10 \mathrm{c}$ & 90 & 81 \\
\hline$*$ Terceiro mês $\left(\mathrm{P}_{3}\right)$ & $65,44 \mathrm{ed}$ & $60,40 \mathrm{ed}$ & 83 & 76 \\
\hline *Quarto mês $\quad\left(\mathrm{P}_{4}\right)$ & $66,88 \mathrm{~d}$ & $60,68 \mathrm{~d}$ & 85 & 76 \\
\hline *Quinto mês $\left(\mathrm{P}_{5}\right)$ & $65,92 \mathrm{~d}$ & $61,46 \mathrm{~d}$ & 83 & 77 \\
\hline * Sexto mês $\quad\left(\mathrm{P}_{6}\right)$ & $63,77 \mathrm{e}$ & $58,98 \mathrm{e}$ & 80 & 73 \\
\hline
\end{tabular}

Nas colunas, médias seguidas da mesma letra dentro de cada lator näo dilerem entre si, pelo teste de lukey, a $5 \%$ de probabilidade. Dados transformados para are sen(P/100) $)^{0.5}$

longo do tempo, o que está de acordo com o trabalho de Almeida (1981) ao estudar o armazenamento das sementes de algodão, quando concluiu que a germinação decresce com o tempo de armazenamento; no entanto, verifica-se, a partir do terceiro mês uma estabilização do poder germinativo e do vigor das sementes de arroz alé o sexto mês, pois eles não diferem significativamente.

Na Tabela 4 encontram-se os valores médios da germinação e vigor das sementes de arroz para a interação Localidade $\mathrm{x}$ Embalagem; verifica-se, nesta labela, que as sementes de arroz conservaram melhor o seu poder germinativo e o vigor, na localidade de Campina Grande $\left(\mathrm{L}_{2}\right)$, onde os dois tipos de embalagem não diferiram significativamente, podendo-se utilizar qualquer um deles para armazenar sementes nesta microrregião; no entanto, esta afirmação contradiz as observações feitas por Gomes (1992) ao estudar o armazenamento de sementes de algodão em Campina Grande, obtendo diferenças significativas entre as embalagens; observa-se ainda que, para os dois tipos de embalagem estudados, as condições ambientais das localidades João Pessoa $\left(\mathrm{L}_{1}\right)$ e Patos $\left(\mathrm{L}_{3}\right)$ interferiram significativamente na qualidade das sementes; analisando-se a localidade de João Pessoa $\left(L_{1}\right)$ nota-se que o recipiente metálico $\left(E_{1}\right)$ conserva melhor a qualidade fisiológica (germinação e vigor) das sementes de arroz, quando comparado com o saco de aniagem $\left(\mathrm{E}_{2}\right)$. Isto ocorreu devido, possivelmente, ao fato de João Pessoa possuir temperaturas e umidades relativas mais elevadas, ficando o material armazenado em embalagem permeável totalmente exposto a essas condições desfavoráveis, contribuindo diretamente para a deterioração das sementes, de forma mais

Tabela 4. Valores médios da germinação e vigor das sementes de arroz para a interação Localidade x Embalagem ${ }^{1}$

\begin{tabular}{|c|c|c|c|c|}
\hline \multirow{3}{*}{ I.ccalidade } & \multicolumn{4}{|c|}{ Embalagem } \\
\hline & \multicolumn{2}{|c|}{ Recipicntes Mctálicos $\left(\mathrm{E}_{1}\right)$} & \multicolumn{2}{|c|}{ Sacos de Aniagem $\left(\mathrm{E}_{2}\right)$} \\
\hline & Gernuinação & Vigor & Gernninação & Vigor \\
\hline João Pessoa $\left(\mathrm{L}_{1}\right)$ & $72,66 \mathrm{bA}$ & $66,58 \mathrm{bA}$ & $55,57 \mathrm{cB}$ & $52,39 \mathrm{cB}$ \\
\hline Campina Grande $\left(\mathrm{L}_{2}\right)$ & $74,66 \mathrm{a \Lambda}$ & 70,56 a $\Lambda$ & $75,48: \Lambda$ & 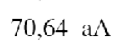 \\
\hline Patos $\left(\mathrm{L}_{3}\right)$ & $68.47 \mathrm{cB}$ & $62,80 \mathrm{cA}$ & $72,44 \mathrm{bA}$ & $64,06 \mathrm{bA}$ \\
\hline
\end{tabular}

Para cada característica avaliada, as médias seguidas pela mesma lerra maiúscula nas linhas e minúsculas nas colunas nã diferem estaristicamente a nível de $5 \%$ de probabilidade, pelo teste de Tukey. Dados transformados para arc sen $(\mathrm{P} / 100)^{0 \text { s }}$ rápida que nas embalagens impermeáveis, confirmando a observação de Aguiar (1982) quando diz que a conservação da qualidade das sementes sob condições ambientais está relacionada ao tipo de embalagem empregada. Para as sementes armazenadas em Patos $\left(\mathrm{L}_{3}\right)$ a embalagem saco de aniagem $\left(\mathrm{E}_{2}\right)$ conservou melhor a viabilidade, pois nesta localidade as condiçōes climáticas caracterizam-se por temperaturas mais elevadas e baixas umidades relativas do ar; consequientemente, nas embalagens permeáveis o teor de água das sementes entra em equilíbrio com as condições ambientais do meio, condições estas que favorecem a manutenção da qualidade fisiológica das sementes; este fato também foi verificado por Lima (1983) ao armazenar sementes de milho em Patos, quando concluiu que a qualidade fisiológica das sementes foi melhor preservada quando elas foram acondicionadas em saco de aniagem.

Os valores médios da germinação e vigor das sementes de arroz para a interação Período x Localidade encontram-se na Tabela 5, na qual se nota que as sementes armazenadas no período inicial e no segundo mês de armazenamento diferem estatisticamente, para as três localidades estudadas, enquanto para os demais períodos as sementes de arroz se conservaram melhor na localidade de Campina Grande; observa-se, também, que a localidade de Patos revela valores de germinação e vigor no final do período de armazenamento superiores aos de João Pessoa. Esta tendência dos resultados confirma a relação entre a manutenção da qualidade fisiológica (germinação e vigor) das sementes e as condições de armazenamento (temperatura e umidade relativa do ar) ou seja, o local que melhor conservou o poder germinativo das sementes foi aquele onde ocorreram as menores temperaturas e umidades relativas do ar.

Tabela 5. Valores médios da germinação das sementes de arroz para a interação Localidade x Período ${ }^{1}$

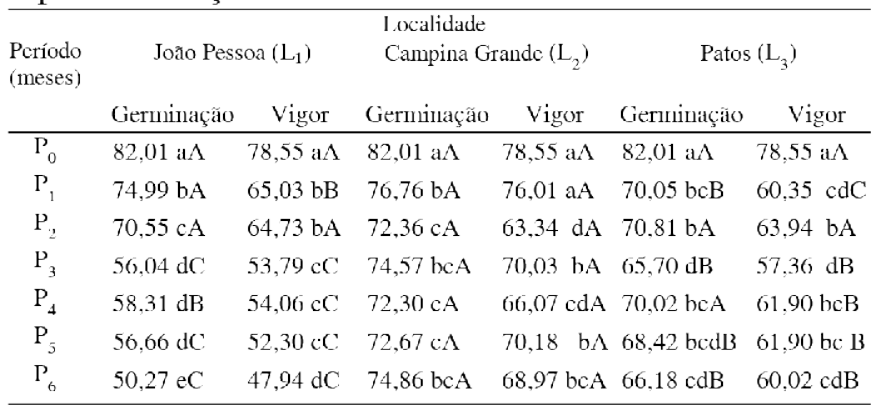

' Para cada característica avaliada, as médias seguidas pela mesma letra maiúscula nas linhas e minúsculas nas colunas nå diferem estatisticamente a nível de $5 \%$ de probabilidade, pelo teste de Tukey. Dados transformados para arc sen( $(\mathrm{P} / 100)^{1 ! \text { : }}$

Sob condições ambientais nota-se que, a medida em que foi aumentando o tempo de armazenamento nas três localidades, houve reduções gradativas do poder germinativo e do vigor das sementes de arroz, fato este verificado também por Ohashi et al. (1991) para sementes de algodão.

Na Tabela 6 apresentam-se os valores médios da germinação e vigor das sementes de arroz para a interação Período $x$ Embalagem e se constata que a preservação das sementes nos recipientes metálicos $\left(\mathrm{E}_{1}\right)$ permitiu uma boa conservação da qualidade fisiológica das sementes em todos os períodos de armazenamento, não havendo diferenças significativas entre as médias observadas do primeiro ao quinto mês. Nas embalagens saco de aniagem $\left(\mathrm{E}_{\text {, }}\right.$ ) ocorreu redução significaliva na viabilidade das sementes depois do terceiro mês de armazenamento, 
mantendo-se até o sexto mês; do terceiro até o sexto mês de armazenamento das sementes, nota-se a existência de diferenças significativas entre as embalagens, mostrando que os recipientes metálicos conservam melhor o poder germinativo e o vigor das sementes de arroz.

Tabela 6. Valores médios da germinação das sementes de arroz para a interação Período x Embalagem ${ }^{1}$

\begin{tabular}{|c|c|c|c|c|}
\hline \multirow{3}{*}{$\begin{array}{l}\text { Período } \\
\text { (meses) }\end{array}$} & \multicolumn{4}{|c|}{ Embalagem } \\
\hline & \multicolumn{2}{|c|}{$\begin{array}{l}\text { Recipientes Metálicos } \\
\left(\mathrm{E}_{1}\right)\end{array}$} & \multicolumn{2}{|c|}{$\begin{array}{c}\text { Sacos de Aniagem } \\
\left(\mathrm{E}_{2}\right)\end{array}$} \\
\hline & Germinação & Vigor & Germinação & Vigor \\
\hline$P_{0}$ & 82,01 aA & $78,55 \mathrm{aA}$ & 82,01 aA & $78,55 \mathrm{aA}$ \\
\hline $\mathrm{P}_{1}$ & $73,03 \mathrm{bA}$ & $66,84 \mathrm{bA}$ & $74,80 \mathrm{bA}$ & $67,95 \mathrm{bA}$ \\
\hline $\mathrm{P}_{2}$ & $69,97 \mathrm{bA}$ & $62,41 \mathrm{cB}$ & $72,52 \mathrm{bA}$ & $65,80 \mathrm{bA}$ \\
\hline $\mathrm{P}_{3}$ & $71,01 \mathrm{bA}$ & $64,87 \mathrm{bcA}$ & $59,86 \mathrm{cB}$ & $55,92 \mathrm{cB}$ \\
\hline $\mathrm{P}_{4}$ & $70,91 \mathrm{bA}$ & $64,52 \mathrm{bcA}$ & $62,84 \mathrm{cB}$ & $56,83 \mathrm{cB}$ \\
\hline $\mathrm{P}_{5}$ & $70,47 \mathrm{bA}$ & $67,04 \mathrm{bA}$ & $61,37 \mathrm{cB}$ & $55,88 \mathrm{cB}$ \\
\hline$P_{6}$ & $66,08 \mathrm{cA}$ & $62,34 \mathrm{cA}$ & $61,46 \mathrm{cB}$ & $55,62 \mathrm{cB}$ \\
\hline
\end{tabular}

${ }^{1}$ Para cada caracteristica avaliada, as médias seguidas pela mesma letra maiúscula nas linhas $\mathrm{c}$ minúsculas nas colunas nào diferem estatisticamente a nível de $5 \%$ de probabilidade pelo teste de Tukey Dados translormados para are $\operatorname{sen}(\mathrm{P} / 100)^{0.5}$

\section{CONCLUSÕES}

De acordo com os resultados obtidos, conclui-se que:

1. As sementes de arroz, armazenadas nos diferentes lipos de embalagem e nas condições ambientais das três localidades da Paraíba, apresentaram as menores perdas no poder de germinação $(4,2 \%)$ e vigor $(6,5 \%)$ na localidade de Campina Grande, no final dos seis meses.

2. As menores perdas verificadas no poder germinativo e no vigor das sementes de arroz nas cidades de João Pessoa, Campina Grande e Patos, no final de seis meses de armazenamento, foram: a) João Pessoa, embalagem metálica com $28,1 \%$ para germinação e $31,5 \%$ para vigor; b) Campina Grande, embalagem saco de aniagem, $4,2 \%$ para germinação e $6,4 \%$ para vigor e c) Patos, embalagem saco de aniagem com $12,6 \%$ para germinação e 26,3 $\%$ para vigor.

3. A melhor localidade para se armazenar as sementes de arroz foi Campina Grande, seguida de Palos e João Pessoa.

5. Em Patos, o saco de aniagem conservou melhor o poder germinativo e o vigor das sementes, em virtude do teor de umidade ter permanecido menor nesta condição.

6. O poder germinativo e o vigor das sementes de arroz nas condições ambientais de João Pessoa mantiveram-se melhor na embalagem impermeável (recipientes metálicos).

\section{REFERÊNCIAS BIBLIOGRÁFICAS}

ALMEIDA, F. de A.C. Efeito da temperatura e umidade relativa do ar sobre a germinação, vigor e teor de umidade de sementes armazenadas de algodão (Gossypium hirsutum L. r. latifolium, HUTCH). Areia: UFPB, 1981. 65p. (Tese de Mestrado).
AGUIAR, P.A.A. Armazenamento e conservação de grãos. I. Noções básicas de conservação. II. Armazenamento e conservação em propriedades agrícolas. Petrolina: EMBRAPA - CPATSA, 1982. 31p. (EMBRAPA - CPATSA, Circular técnica, 10).

BACCHI, O. Estudos sobre a conservação de sementes. 3 Trigo. Bragantia, Campinas, v.17, n.15, p.205-12, 1958.

BARRETO, A.N. Diagnóstico da cultura do arroz no Estado da Paraíba. João Pessoa, 1986. 7p.

BRASIL, Ministério da Agricultura. Regras para análises de sementes. Brasília: 1992. 365p.

FUNDAÇÃO IBGE. Rio de Janeiro, R.J. Anuário estatístico do Brasil. Rio de Janeiro, 1991. 853p.

GOMES, F.P. Curso de estatística experimental. Piracicaba: 10 ed. NOBEL, 1982. 430p.

GOMES, J.P. Comportamento da germinação e vigor de sementes de algodão herbáceo $\mathrm{em}$ diferentes tipos de embalagem, tratamentos e condições de conservação durante a sua armazenagem. Campina Grande: UFPB, 1992. 89p. (Tese de Mestrado).

LIMA, A.L. de Efeitos de ambientes sobre tipos de embalagem e período de armazenamento, na qualidade fisiológica de sementes de milho (Zea mays $L$.). Areia: UFPB, 1983. 47p. (Tese de Mestrado).

MIRANDA, P. Conservação de sementes de sorgo (Sorghum vulgare Pers.). In: SEMINÁRIO PANAMERICANO DE SEMENTES, 5. Boletim Técnico do Instituto de Pesquisas Agronômicas de Pernambuco. Recife, v.21, p.27-36, 1967.

OHASHI, O.N.B.; CARVALHO, J.E.U. de; CORRÊA, J.R.V.; FIGUEIRÊDO, F.J.C. Conservação de sementes de algodão sob condições tropicais úmidas. Belém, EMBRAPA - CPATU, 1991. 32p. (EMBRAPA - CPATU. Boletim de Pesquisa, 117).

PAIVA, J.B.; ALBUQUERQUE, J.J.L.; AGUIAR, P.A.A.; CYSNE, F.M.M. Efeito do tempo de estocagem e tipos de embalagem na germinação de sementes de milho, arroz e feịjão-de-corda. Ciências Agronômicas, Fortaleza, v.2, n.1, p.1-8, 1972.

PANIAGO, C.F.A.; ANDRADE, D.F. de; TSURUTA, J.H.; CAMARGO NETO, J.; FESTA, M.M.; PEDROSO Jr. M.R.; PACHECO, O.I.P.; EVANGELISTA, S.R.M. Software Científico. SOC. Campinas - SP, EMBRAPA/ NITA, 1987.

PIMENTEL, M.L.; AGUIAR, P.A.A.; SILVA, M.C.L. da. Conservação de sementes armazenadas nas diversas zonas fisiográficas do Estado de Pernambuco. Pesquisa Agropecuária., Recife, v.2, n.1, p.61-72, 1978.

SANTOS, E.S. dos; BOSCO, J. Tecnologias geradas c/ou adaptadas à agropecuária paraibana. João Pessoa: EMEPA, 1984. 47p. (EMEPA. Documentos,5)

SNEDECOR, G.W. Métodos estatísticos aplicados a la investigation agricola y biologica. México: Continental, 1966. 622p. 